\title{
The Effects of Feeding and Various Hormones on the Glucose Tolerance of the Sand Rat (Psammomys Obesus)*
}

\author{
Bernard N. Brodoff, Juan C. Penhos and R. Levine \\ with the technical assistance of RANDOLPH WHITE
}

Department of Medicine, New York Medical College, New York City

Summary. The key finding in our study is a dimin. ished tolerance for glucose in the potentially diabetic vegetable-fed sand rat, induced or aggravated by brief periods of food deprivation. This "starvation diabetes" may represent an ideal experimental model for study of the mechanism involved in the development of diabetes in the chow-fed animal.

Effet du régime et de différentes hormones sur la tolérance au glucose du rat du sable (Psammomys obesus).

Résumé. L'observation principale que nous rapportons est celle d'une diminution de la tolérance au glucose chez le rat des sables potentiellement diabétique, même soumis à un régime consistant exclusivement en légumes. Cette intolérance est induite ou aggravée par des périodes même brèves de jeûne. Ce "diabète de la faim» pourrait bien s'avérer être un diabète expérimental idéal pour l'étude de la pathogénèse du diabète qu'on observe chez l'animal soumis à un régime normal, plus riche en calories.
Wirkung von Ernährung und von einigen Hormonen auf die Glucose-Toleranz der Sandratte (Psammomys obesus).

Zusammenfassung. Das Hauptergebnis unserer Untersuchung ist die Beobachtung einer verminderten Toleranz für Glucose in der potentiell diabetischen Sandratte, selbst bei rein pflanzlicher Ernährung. Verursacht oder verschlimmert wurde dieser Zustand durch kurze Perioden von Nahrungsentzug. Dieser ,Hungerdiabetes“ könnte ein ideales Versuchsmodell darstellen, und die Aufklärung des diabetogenen Mechanismus bei normaler Laboratoriumskost erleichtern.

Key-words: Spontaneous Diabetes, Sand rat, Psammomys obesus, Prediabetes, Potential diabetes, Preclinical diabetes, Starvation diabetes, Phenformin, Growth hormone, Cortisone, Glucagon, Insulin response.

\section{Introduction}

Diabetes mellitus develops in the sand rat (Psammomys Obesus) when Purina laboratory chow is substituted for an all vegetable diet [12]. These animals in their native habitat, the dried-out wadi in the desert regions of North Africa and the Near East, feed on large amounts of vegetation (Family Chenopediacae) with a high water, salt and oxalic acid content [11]. As far as is known, diabetes does not develop in the wild sand rat. The syndrome of the captive animals fed Purina laboratory chow is characterized by hyperglycemia, elevated plasma insulin levels except during ketoacidosis, diminished extractable pancreatic insulin, glycosuria, and pathological lesions, including cataracts, B-cell degranulation vacuolization of the pancreatic islet tissue and glycogen nephrosis $[4,5,10]$. The animals vary in their diabetogenic susceptibility, not all developing permanent or fulminating diabetes on show [5].

The sand rat appears to be a potential diabetic on the all-vegetable diet even before chow feeding has been administered. Either excessive feeding or starvation for brief periods impairs carbohydrate tolerance. The present study deals with the effects of feeding, the administration of various hormones and of phenformin on the accelerated "starvation diabetes" seen in the sand rat.

* This work was supported by a grant from the United States Public Health Service (AM 10675-01).

\section{Methods}

Sand rats trapped in Egypt were used in the experiments. All animals were fed fresh vegetables (beet roots, beet greens, spinach and carrots) ad libitum with no additional water available. White rats (Wistar strain), maintained on Purina laboratory chow were used in all studies for comparative purposes. Six-hour oral GTT (300 mg glucose/100 g rat) were performed after an overnight (15 hour) fast and after a two-hour fast in untreated rats and in rats pretreated with cortisone (2.5 mg per rat for 7 days) and GH $(1 \mathrm{mg} /$ $100 \mathrm{~g}$ rat for 7 days $)$. Phenformin $(2.5 \mathrm{mg} / 100 \mathrm{~g}$ rat $)$ and glucose were administered orally (at zero time) to overnight-fasted rats. Two-hour Insulin Tolerance Tests $(1 / 2$ unit insulin $/ 100 \mathrm{~g}$ rat) and four-hour Insulin Tolerance Tests with glucose were performed on overnight-fasted rats. Glucagon tolerance $(50 \mu \mathrm{g} / 100 \mathrm{~g}$ rat) was determined on fed rats. For the two-hour fasted rats, vegetables or chow were ground up in a Waring blender and administered by stomach tube to the sand and white rats respectively, two hours before the performance of the GTT. Blood was obtained from the tip of the tail, and blood sugars determined on the Technicon auto-analyzer using the standard ferricyanide micro-determination technique.

\section{Results}

All comparisons are based on changes from fasting blood sugar levels. In animals fasted overnight the blood sugar rise one and two hours after the glucose 
load, was considerably greater in the sand rat than in the white rat, whereas the fasting and six-hour blood sugar levels were significantly lower in the sand rat $(p<0.05$ at 0 hours and $<0.01$ at 6 hours) (Fig. 1).
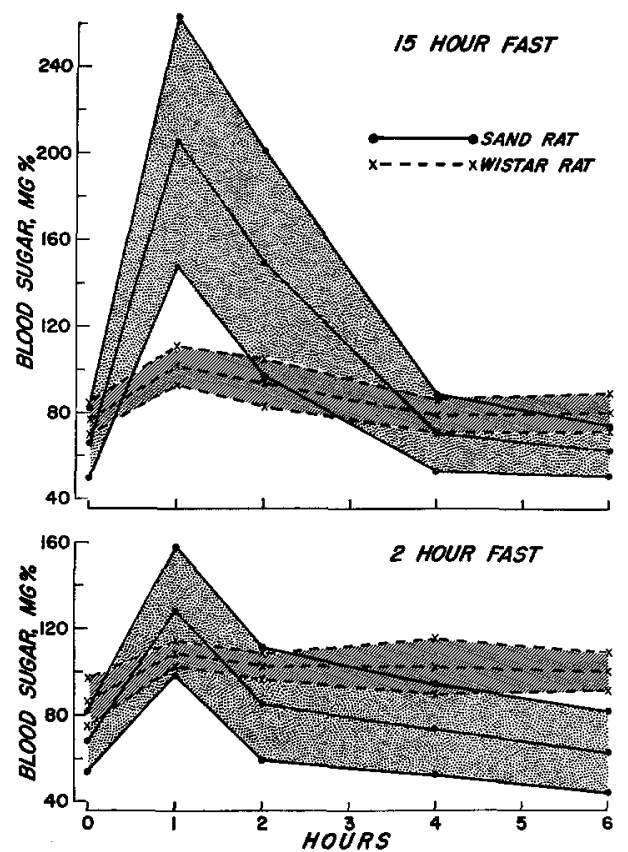

Fig. 1. Gucose tolerance tests on Sand and Wistar rats fasted 15 and 2 hours Total width of each shaded area equals two standard deviations. Figures in parentheses denote number of rats in each experiment. All $p$ values are based on a test comparing the changes from zero time in the two species. Only significant species differences are noted. 15-hour fast: Sand rat $(n=23$ at 0 and 1 hour; 17 at 2 hours; 14 at 4 and 6 hours); White rat (8) $p<0.01$ at 1 and 2 hours). 2 -hour fast: Sand rat $(n=13$ at 0,1 and 2 hours; 7 at 4 and 6 hours); White rat (4) $p<0.05$ at 1 hour)

In fed animals (two-hour fasted) the changes in blood sugar levels become comparable in the two species although the increase in the blood sugar of the sand rat at one hour was still significant (Fig. 1). In general, animals treated with cortisone and growth hormone showed changes similar to those in the control groups with certain exceptions: the growth hormone-treated sand rat, fasted overnight, had a more marked hyperglycemia at two hours $(212 \mathrm{mg} \%)$; whereas the fed, growth hormone-treated sand rat showed a higher initial blood sugar, and a lower blood sugar at four and six hours, than the control and cortisone-treated sand rats; furthermore both the fed, cortisone and growth hormone treated sand rats had lower blood sugars at four and six hours than did the corresponding white rats (Fig. 2 and 3). There were no significant effects of fasting versus feeding, or of hormone pretreatment in the white rat.

Both species, after an overnight fast, showed similar absolute decreases in blood glucose after insulin (Fig. 4). After the simultaneous administration of oral glucose and insulin, however, elevated blood sugars were noted in the sand rat when compared with the white rat, throughout the four-hour test (Fig. 4).
However, when compared with the effect of glucose alone, the addition of insulin lowered the blood sugar at one and two hours in the sand rat.

Phenformin had no effect on the glucose tolerance
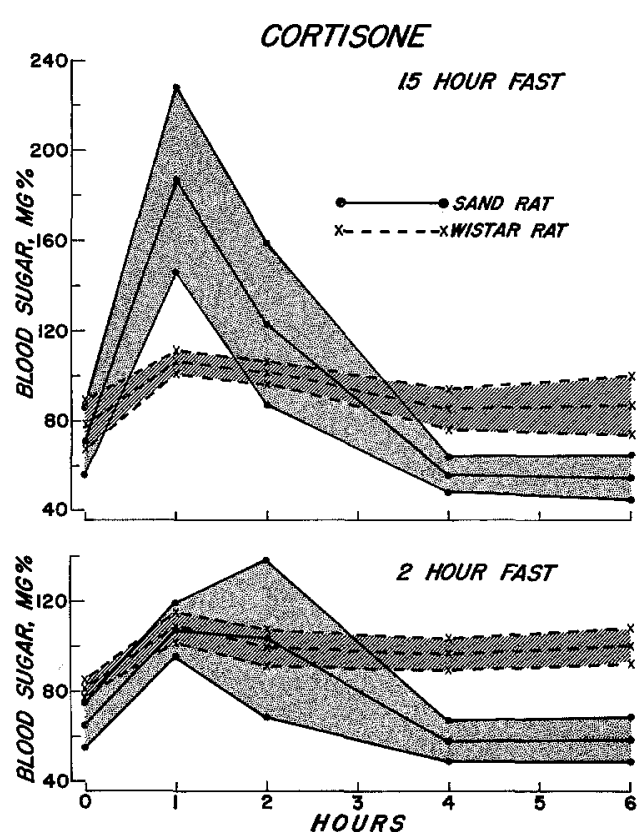

Fig. 2. Glucose tolerance tests on Sand and Wistar rats fasted 15 and 2 hours after pretreatment with cortisone

15-hour fast: Sand rat (5); White rat (4) $p<0.05$ at 1 hour. 2 -hour fast: Sand rat (4); White rat (4) $p<0.01$ at 4 and 6 hours

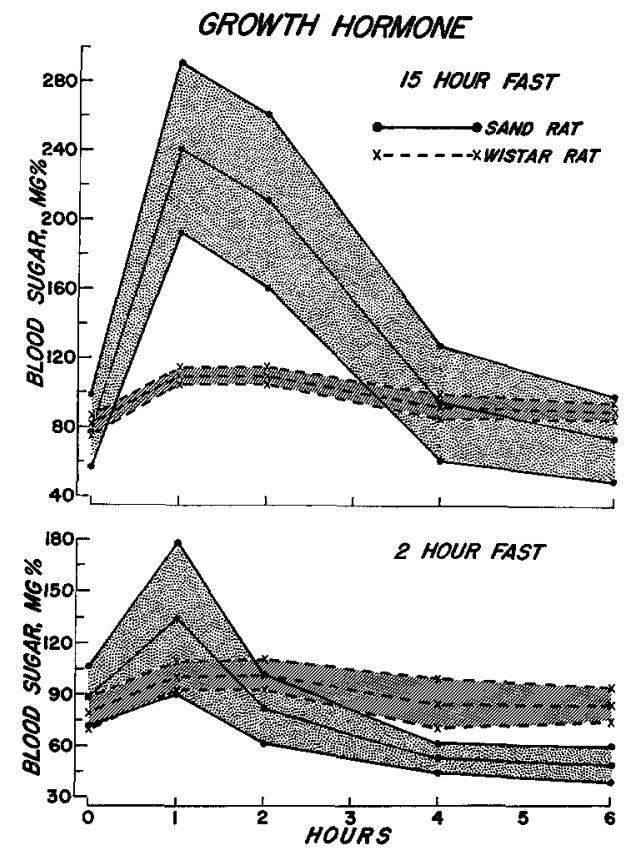

Fig. 3. Glucose tolerance tests on Sand and Wistar rats fasted 15 and 2 houps after pretreatment with growth hormone.

15-hour fast: Sand rat (7); White rat (6) $p<0.01$ and 1 and 2 hours. 2-hour fast: Sand rat (5); White rat (4) $p<0.05$ at 2 hours; $p<0.01$ at 4 and 6 hours 
of the white rat but significantly lowered the blood sugar of the sand rat at one and two hours (Fig. 5). Glucagon administration to fed rats resulted in maximal blood sugars in the white rat at 15 minutes with hyperglycemia lasting for one hour. In the sand rat maximal levels were noted at one and two hours (Fig. 6).

\section{Discussion}

The effect ot fasting in decreasing the tolerance of animals and humans for carbohydrate is well established $[1,7]$. In Wistar rats $7-10$ days are required for "starvation diabetes" to develop [7]. Sand rats fasted overnight however, were unable to dispose of an oral glucose load without marked elevation of the blood sugar at one and two hours of the glucose tolerance. Prefeeding, a stimulus for insulin secretion, improved the glucose disposal mechanism in the sand rat. This was also true after intraperitoneal glucose administration [6], thus eliminating delayed absorption as a critical factor in the improved glucose tolerance. It would appear that the overnight-fasted sand rat is either insulin resistant, or has an in-adequate insulin secretory response to glucose.

Although the ITT showed a normal hypoglycemic response in the overnight fasted sand rat, the blood sugar response with the added stress of a glucose load in the IGTT suggests insulin resistance in this species.

The resistance of the rat to the diabetogenic effects of cortisone and growth hormone are well known [2, 15]. It is not surprising, therefore, that the white rat maintained on a regular chow diet showed no breakdown of carbohydrate tolerance after pretreatment with these hormones. The fasted sand rat also responded to the increased flux of glucose after cortisone treatment with an unchanged glucose tolerance, and lower values at four and six hours in the fed animal, presumably due to increased insulin secretion. After growth hormone administration some further deterioration of carbohydrate tolerance was noted in the fasted sand rat, whereas this hormone caused a significant decline in blood sugar in the fed animal at four and six hours after glucose administration. This is consistent with the concept that growth hormone leads to increased insulin production and release [8], while simultaneously inhibiting the action of insulin peripherally [3]. In the sand rat these effects of growth hormone alter the glucose tolerance conspicuously, in contrast to the white rat where they seem to neutralize each other.

The exact mechanism whereby phenformin lowers blood sugar, and its site of action, hepatic and/or peripheral, are unknown. In non-lethal doses, however, phenformin has a significant effect only in diabetic animals $[13,9]$. For this reason its hypoglycemic action in the fasted sand rat maintained on vegetable feed is of particular interest, suggesting that the accelerated "starvation diabetes" of the sand rat may be used as a mechanistic model for the development of diabetes in the chow-fed animal.
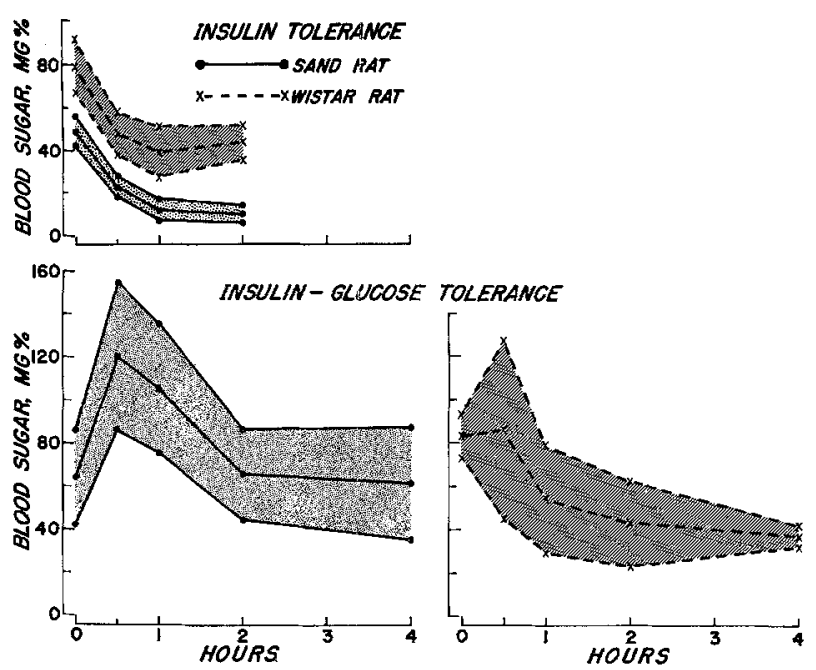

Fig. 4. Insulin and insulin glucose tolerance tests on Sand and Wistar rats after a 15-hour fast

ITT: Sand rat (4); White rat (4). IGTT: Sand rat (6); White rat (6) $p<0.05$ at $1 / 2$ and 1 hour; $p<0.01$ at 2 and 4 hours

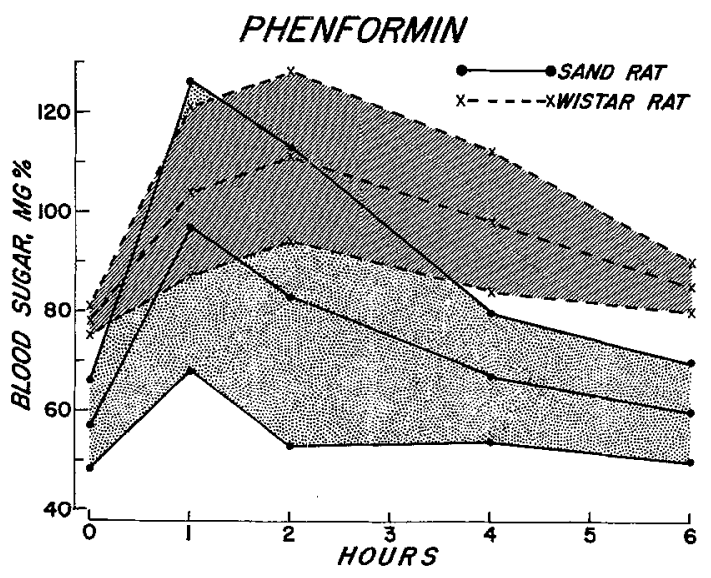

Fig. 5. Glucose tolerance tests on Sand and Wistar rats after phenformin administration at zero time Sand rat (9); White rat (4)

\section{RESPONSE TO GLUCAGON}

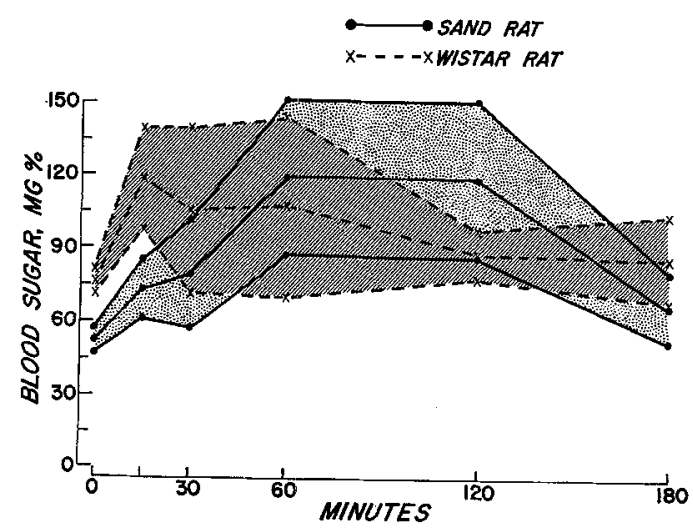

Fig. 6. Qlucagon tolerances on 15-hour fasted Sand and Wistar rats Sand rat (5); White rat (4) $p<0.05$ at 15 minutes; $p<0.05$ at 1 and 2 hours 
The reason for the delayed and prolonged response to glucagon in the sand rat is at present unknown and can only be clarified by examination of plasma insulin levels.

Sand rats imported from Egypt in 1964 developed fulminating diabetes (9 of 10) when fed laboratory chow [10], whereas animals imported in 1965 by the same investigators were resistant to the development of diabetes. Our own experience with the "starvation diabetes" has been similar. In a group of animals imported from Egypt recently, only 30\% showed the marked elevation of blood sugar at one hour seen in virtually all of the original group of sand rats reported on in this paper. This and the phenformin effect lead us to believe that the starvation curve may represent a model for the diabetes seen in the chow-fed animal; and studies are currently in progress in our laboratory to clarify the mechanism of this finding.

Acknowledgements. Grateful appreciation is extended to Dr. Harry H. Hoogstraat, United States Naval Medical Research Unit No. 3, Cairo, Egypt, the United States Navy, and Dr. K. SohMtot-NIELSEN for supplying a stock of sand rats. The growth hormone used in these studies was a gift from the Endocrine Study Section, National Institutes of Health, and the Phenformin from Dr. H. SADOW, U.S. Vitamin and Pharmaceutical Corp.

\section{References}

[1] Berguan, H.C., and D.R. DRURY: Effect of feeding and fasting on sugar utilization of eviscerated rabbits. Proc. Soc. exp. Biol. 37, 414-417 (1937).

[2] Christophe, J., R. Bellens, J.C. Demaret, V. Conard and W. Gepts: Effect de doses variables de cortisone sur le metabolisme glucidique et la croissance ponderale du rat. Ann. Endocr, 19, 23-28 (1958).

[3] Evars, H.M., K. Meyer, M. E. Stmpson, and F.T. RmicherT: Disturbance of carbohydrate metabolism in normal dogs injected with hypophyseal growth hormone. Proc. Soc. exp. Biol. 29, 857-858 1932).
[4] Hackel, D.B., L.A. Frohman, E. Mikat, H. E. LeBovitz, K. SchMIDT-NIELSEN and T.D. KINNEY: Review of current studies on effect of diet on the glucose tolerance of the sand rat (Psammomys obesus). Ann. N. Y. Sci. 131, $459-463$ (1956).

[5] - - - - Effect of diet on the glucose tolerance and plasma insulin levels of the sand rat (Psam momys obesus). Diabetes 15, 105-114 (1966).

[6] -., and H.E. LeBovitz: Unpublished observations.

[7] INGLE, D.J.: Experimental glycosuria in the rat. Recent Progr. Hormone Res. 21, 229 (1948)

[8] Kinash, B., J. MadDougali, M.A. Evays, F.E Bryans and R.E. Haist: Effects of anterior pitui. tary extracts and of growth hormone preparations on the islets of Langerhans and the pancreas. Diabetes $2,112-121$ (1953).

[9] Madison, L.M. and R.H. Unger: Effect of phenformin on peripheral glucose utilization in human dia. betic and nondiabetic subjects. Diabetes 9, 202-206 (1960).

[10] Mmkr, E., A.A. LIKE J.S. SOkLdNer, J. STEINKe and G.F. CaHILL, JR.: Acute ketotic-type diabetic syndrome in sand rats (Psammomys obesus) with special reference to the pancreas. Metabolism 15, $749-760$ (1966).

[11] Schmidt-Ntelsen, K.: Desert Animals pp. 182-186 Oxford: Clarendon Press 1964.

[12] - , H.B. Haines and D.B. HAOKEL: Diabetes mellitus in the sand rat induced by standard diets. Science 143, 689-690 (1964).

[13] Ungar, G., L. Freedman and S.L. Shapiro: Pharmacologic studies of a new oral hypoglycemic drug. Proc. Soc. exp. Biol. 95, 190-192 (1957).

[14] UNGER, R.H., A.M. EisEntratT and L.L. MAdison: The effects of total starvation upon the levels of circulating glucagon and insulin in man. J. clin. Invest, 42, 1031-1039 (1963).

[15] YodNG, F.G.: Growth hormone and experimental diabetes. J. clin. Endocr. 11, 531-536 (1951).

Bernard N. Brodoff, M. D. New York Medical College Flower and Fifth Avenue Hospitals Fifth Avenue and 106th Street New York, N. Y., U.S.A. 